\title{
Neck circumference as a discriminator of obesity in older women enrolled in a physical activity program
}

\section{Perímetro do pescoço: discriminador de obesidade em idosas praticantes de atividade física}

\author{
Daniel Rogério Petreça ${ }^{1}$ \\ Enaiane Cristina Menezes ${ }^{2}$ \\ Paula Fabrício Sandreschi ${ }^{3}$ \\ Felipe Fank ${ }^{4}$ \\ Giovana Zarpellon Mazo²
}

Abstract - The aim of this study was to evaluate neck circumference (NC) as a discriminator of overweight and obesity and to establish cut-off points for physically active older women. The sample consisted of 170 older women $(69.5 \pm 6.8$ years $)$ practicing physical activity. Anthropometric measures (body weight, height, waist circumference - WC, and $\mathrm{NC}$ ) were obtained and the body mass index (BMI) was calculated. Correlation analysis was performed and ROC curves were constructed. $\mathrm{NC}$ was significantly correlated with $\mathrm{BMI}(\mathrm{rho}=0.656 ; \mathrm{p}<0.0001)$ and $\mathrm{WC}(\mathrm{r}=0.561 ; \mathrm{p}<0.0001)$. Correlating BMI with NC, areas under the ROC curve of $0.819(\mathrm{p}=0.0001)$ for overweight and of $0.902(\mathrm{p}=0.0001)$ for obesity were obtained, with suggested cut-off points of 33.07 and $34.05 \mathrm{~cm}$, respectively. Correlating WC with NC, areas under the ROC curve of $0.711(p=0.0014)$ for moderate risk (WC) and of $0.864(\mathrm{p}=0.0001)$ for high risk were obtained, with suggested cut-off points of 32.15 and $34.15 \mathrm{~cm}$, respectively. NC was associated with BMI and WC. An $\mathrm{NC} \geq 34 \mathrm{~cm}$ was a risk factor for obesity and abnormal body fat distribution in the older women studied. This anthropometric parameter is an alternative to discriminate overweight and obesity in physically active older women.

Key words: Anthropometry; Motor activity; Neck; Obesity; ROC curve.

Resumo - Objetivou-se analisar o perímetro de pescoço (PPescoço) como um método discriminador de sobrepeso e obesidade e estabelecer pontos de corte para idosas praticantes de atividade física. A amostra foi composta por 170 idosas (69,5 $\pm 6,8$ anos) praticantes de atividade física. Foram realizadas medidas antropométricas de massa corporal, estatura, perímetro de cintura (PCintura) e do pescoço (PPescoço). Também foi calculado o indice de massa corporal (IMC) e realizada a estatistica correlacional e curvas $R O C$. O PPescoço correlacionou significativamente com o IMC (rho =0,656; $p<0,0001)$ e com o PCintura $(r=0,561 ; p<0,0001)$. Ao relacionar $I M C$ com PPescoço, obteve-se valores para área da curva ROC de 0,819 ( $p=0,0001)$ para sobrepeso e 0,902 (p=0,0001) para obesidade, além de pontos de corte sugeridos de 33,07 cm e $34,05 \mathrm{~cm}$, respectivamente. Ao relacionar PCintura com o PPEscoço, obteve-se valores para área curva ROC de 0,711 ( $p=0,0014$ ) para risco moderado (PCintura) e 0,864 ( $p=0,0001$ ) para alto risco, além de pontos de corte sugeridos de $32,15 \mathrm{~cm}$ e 34,15, respectivamente. O PPescoço apresentou relação com o IMC e o PCintura. O PPescoço $\geq 34 \mathrm{~cm}$ apresentou-se ser o valor de risco para obesidade e distribuição de composição corporal em idosas deste estudo. Essa medida antropométrica é uma alternativa para discriminar o sobrepeso e obesidade de idosas praticantes de atividade física.

Palavras-chave: Antropometria; Atividade motora; Curva ROC; Obesidade; Pescoço.
1 University of Contestado. Nucleus of Research in Collective Health and Environment. Mafra, SC. Brazil.

2 State University of Santa Catarina. Postgraduate Program in Human Movement Sciences. Gerontology Laboratory. Florianopolis, SC. Brazil.

3 Federal University of Santa Catarina. Postgraduate Program in Physical Education. Florianopolis, SC. Brazil.

4 State University of Santa Catarina. Florianopolis, SC. Brazil.

Received: 11 April 2017 Accepted: 22 June 2017 


\section{INTRODUCTION}

Overweight and obesity are considered major public health problems ${ }^{1}$ and are increasing at an alarming rate throughout the world in both developed and developing countries and in different ages ${ }^{2}$. Obesity is associated with different comorbidities such as cardiovascular and metabolic diseases ${ }^{2}$, functional limitations and disabilities, in addition to compromising the quality of life of affected individuals ${ }^{3}$.

In recent years, there has been discussion about the selection of more accurate (for research purposes) and more convenient (for clinical practice) anthropometric measurements for the diagnosis of obesity ${ }^{4}$, including body mass index (BMI) and waist circumference (WC) $)^{5}$. Although BMI and WC have limitations ${ }^{6,7}$, these parameters are used because of their noninvasive, relatively simple and inexpensive measurement ${ }^{8}$. In addition, they are associated with factors of morbidity and mortality ${ }^{1-5}$.

Neck circumference (NC) is a marker of upper body subcutaneous adipose tissue distribution and is a relatively new method to differentiate normal and abnormal fat distribution ${ }^{9}$. Neck circumference is an indicator associated with high blood pressure ${ }^{10,11}$, metabolic syndrome ${ }^{12-14}$, insulin resistance and triglycerides ${ }^{11}$, type 2 diabetes ${ }^{9,12,14,15}$, cardiovascular risk factors $^{15,16}$, and visceral fat ${ }^{12,13,17}$. This marker has been measured in children and adolescents ${ }^{10,18}$, adults ${ }^{12,15,16}$, and older adults ${ }^{13}$.

Within this context, it is important to compare NC with other anthropometric measurements and to establish cut-off points for physically active Brazilian older women, considering that this anthropometric parameter provides consistent results regarding the accumulation of upper body subcutaneous fat $\mathrm{t}^{9,17}$. Moreover, $\mathrm{NC}$ can be used in clinical practice and in epidemiological studies as a simple, reliable, rapid, low-cost indicator, which is correlated with other commonly used anthropometric parameters ${ }^{9,17}$. However, studies applying this method to physically active older adults are sparse, especially in Brazi $1^{11,12,19}$, and no reference parameters are available for this population.

In view of these considerations, the objective of the present study was to evaluate $\mathrm{NC}$ as a discriminator of overweight and obesity and to establish cut-off points for older women enrolled in a physical activity program.

\section{METHODOLOGICAL PROCEDURES}

\section{Study design, population and sample}

This was a cross-sectional, descriptive, correlation study. The population consisted of about 300 older adults participating in the extension program of the Senior Study Group (GETI in the Portuguese acronym) conducted at the Center of Health and Sports Sciences (CEFID) of the State University of Santa Catarina (UDESC).

Non-probability sampling was used for selection of the sample. The following inclusion criteria were adopted: age of 60 years or older, par- 
ticipation in the test battery offered by GETI in March 2016, and female gender. The gender choice was due to the large participation of women in this type of intervention ${ }^{20}$. Older women who were unable to perform the anthropometric tests were excluded. Thus, the final sample consisted of 170 older women.

\section{Instruments and data collection procedures}

Anamnesis interviews were held for characterization of the participants to obtain sociodemographic data and health conditions. The data were collected in the first week of March 2016.

Body weight, height and circumferences (waist and neck) were measured with a Plenna Wind ${ }^{\varpi}$ digital scale (MEA 07710), WCS $^{\oplus}$ stadiometer $(217 \mathrm{~cm})$ and $\mathrm{CESCORF}^{\circledast}$ anthropometric tape measure, respectively. The variables were measured in the following order: body weight, height, WC, and NC. One evaluator obtained the body weight, height and WC measurements and another performed the NC measurements. Both evaluators were trained in the data collection by an instructor certified by the International Society for the Advancement in Kinanthropometry (ISAK) Level 3.

Body weight (in $\mathrm{kg}$ ) was measured with the participant standing barefoot and wearing only light clothing. For the measurement of height, the participant was placed standing barefoot, feet parallel to each other, with the posterior region of the heels, pelvic girdle, shoulder girdle and occipital region against the stadiometer and the head in the Frankfurt plane. At the end of an inspiration, the cursor was positioned at an angle of $90^{\circ}$ to the scale, touching the highest point of the participant's skull, and the measurement was obtained in meters $(\mathrm{m})$. Body weight and height were measurement once.

Waist circumference was measured at the narrowest point between the umbilical scar and iliac crest. For the measurement, the participant was placed standing with the arms crossed over the chest. The evaluator was positioned in front of the subject and the measurement was obtained at the end of a normal expiration. The neck circumference, as well as the other measurements, were performed according to the protocol proposed by ISAK ${ }^{21}$. For this purpose, the participant assumed a relaxed sitting position, with the arms hanging freely at the side and the head positioned in the Frankfurt plane. The circumference of the neck (in $\mathrm{cm}$ ) was measured immediately above the thyroid cartilage. Two measurements of WC and $\mathrm{NC}$ were obtained.

After collection of the anthropometric measurements, the BMI was calculated as the body weight $(\mathrm{kg})$ divided by the square of height $(\mathrm{m})$. The cut-off values recommended by the World Health Organization were used for the classification of BMI and WC $(2,22)$. For BMI, a value $<18.5$ $\mathrm{kg} / \mathrm{m}^{2}$ was classified as low weight, 18.5 to $24.9 \mathrm{~kg} / \mathrm{m}^{2}$ as normal weight, 25.0 to $29.9 \mathrm{~kg} / \mathrm{m}^{2}$ as overweight, and $>30 \mathrm{~kg} / \mathrm{m}^{2}$ as obesity (2). For WC, a value $<79.9 \mathrm{~cm}$ was classified as normal, 80 to $88 \mathrm{~cm}$ as moderate risk, and $>88 \mathrm{~cm}$ as high risk ${ }^{22}$. 


\section{Ethical aspects}

The study was approved by the Ethics Committee of UDESC (Protocol 052406/2015). All participants received detailed information about the objective of the study and signed the free informed consent form.

\section{Data analysis}

Descriptive statistics and correlation analysis were used. The intraobserver technical error of measurement was calculated for $\mathrm{NC}^{23}$. Normality of the data was verified using the Kolmogorov-Smirnov test. For analysis of the correlation between NC, BMI and WC, Pearson's test was used for parametric data and Spearman's test for nonparametric data. Bland-Altman plots were constructed to evaluate the limits of agreement between $\mathrm{NC}$, $\mathrm{BMI}$ and WC. For this analysis, Z-scores were calculated for NC, BMI and $\mathrm{WC}$ to remove the unit of measurement.

Receiver operating characteristic (ROC) curves were constructed to determine the sensitivity and specificity of $\mathrm{NC}$ in relation to BMI and WC, identifying the total area under the curve and the $95 \%$ confidence interval. In addition, cut-off points were established according to the best sensitivity and specificity for $\mathrm{NC}$ in relation to BMI and WC.

All analyses were performed using the SPSS $^{\circledast} 20.0$ program, except for the cut-off points suggested by the ROC curve which were obtained with the MedCalc ${ }^{\oplus}$ program. A level of significance of 5\% was adopted in all analyses.

\section{RESULTS}

The participants in the study had a mean age of $69.5(\mathrm{SD}=6.8)$ years. With respect to sociodemographic characteristics, $40.6 \%(n=69)$ of the women were married and 32.5\% ( $\mathrm{n}=55)$ had completed high school. Most older women had a good perception of their health status $(54.9 \%$; $=93)$ and had some disease $(81.8 \% ; \mathrm{n}=137)$. The most frequent diseases were arterial hypertension (43.9\%; $n=74)$, arthrosis $(20.1 \% ; n=34)$, and diabetes $(17.7 \% ; n=30)$. Analysis of risk behaviors showed that $98.8 \%(n=168)$ of the participants did not smoke. In addition to the activities offered by the university program, $51.5 \%(n=87)$ of the older women performed other physical activities.

Table 1 shows the descriptive values of body weight, height, BMI, WC, and NC. Calculation of the intraobserver technical error of measurement for $\mathrm{NC}$ revealed an absolute error of 0.58 and a relative error of $1.65 \%$. For $\mathrm{WC}$, the absolute error was 3.9 and the relative error of $0.8 \%$.

According to the BMI cut-off points, $15.4 \%$ of the participants were classified as normal weight, $39.6 \%$ as overweight, and $43.2 \%$ as obese. Only $1.8 \%$ of the women were low weight. With respect to WC, $14.8 \%$ of the women were classified as normal, $20.7 \%$ as moderate risk, and $64.5 \%$ as high risk.

Spearman's test revealed a significant correlation between BMI and NC (rho $=0.656 ; p<0.0001$ ) (Figure 1A). An r value of 0.561 was obtained for the correlation between NC and WC $(p<0.0001)$ (Figure 1C). 
Table 1. Descriptive values of the anthropometric variables of physically active older women $(n=170)$.

\begin{tabular}{lcccc}
\hline \multirow{2}{*}{ Variable } & \multirow{2}{*}{ Mean } & \multirow{2}{*}{ SD } & \multicolumn{2}{c}{ Range } \\
\cline { 4 - 5 } & & & Minimum & Maximum \\
\hline Body weight $(\mathrm{kg})$ & 68.8 & 11.3 & 35.0 & 104.3 \\
Height $(\mathrm{cm})$ & 153.0 & 6.0 & 139.0 & 173.5 \\
\hline Body mass index $\left(\mathrm{kg} / \mathrm{m}^{2}\right)$ & 29.4 & 4.6 & 16.2 & 42.9 \\
Neck circumference $^{*}(\mathrm{~cm})$ & 34.6 & 2.6 & 28.1 & 40.8 \\
Waist circumference $^{*}(\mathrm{~cm})$ & 91.8 & 12.1 & 60.5 & 122.0 \\
\hline
\end{tabular}

* Mean of two measurements. SD: standard deviation.

The Bland-Altman plots illustrated in Figure 1B and 1D show a higher concentration of points at the $95 \%$ limit of agreement $( \pm 1.96 \mathrm{SD})$ and that the mean difference in $\mathrm{Z}$-scores of the two tests was equal or close to zero.

Figure 2 shows the area under the ROC and 95\% confidence interval of $\mathrm{NC}$ in relation to $\mathrm{BMI}$ (overweight and obesity) and WC (moderate risk and high risk), with the observation of a significant difference.

An area under the ROC curve of 0.819 was obtained for NC in relation to BMI for women classified as overweight. The most adequate NC cut-off point was $33.07 \mathrm{~cm}$. Using this cut-off, $\mathrm{NC}$ was able to predict a normal BMI in $86.2 \%$ of the women and overweight in $64.2 \%$ (Table 2). The area under the ROC for $\mathrm{NC}$ in relation to $\mathrm{BMI}$ for women classified as obese was 0.902 . The most adequate NC cut-off point was $34.05 \mathrm{~cm}$. Using this cut-off, $\mathrm{NC}$ was able to predict a normal BMI in $93.1 \%$ of the women and obesity in $82.4 \%$ (Table 2).

The area under the ROC curve for $\mathrm{NC}$ in relation to $\mathrm{WC}$ was 0.711 for women classified as moderate risk. A cut-off point of $\mathrm{NC}$ of $32.15 \mathrm{~cm}$ was the most adequate in terms of sensitivity and specificity. Using this cut-off, NC was able to predict normal WC in $56.0 \%$ of the women and a moderate risk in $82.9 \%$ (Table 2). For women classified as high risk, the area under the ROC curve for $\mathrm{NC}$ in relation to $\mathrm{WC}$ was 0.864 . The most adequate NC cut-off was $34.15 \mathrm{~cm}$. Using this cut-off, $\mathrm{NC}$ was able to discriminate normal WC in $88.0 \%$ of the women and a high risk in $72.7 \%$ (Table 2).

Table 2. Cut-off values, sensitivity, specificity and p-value of neck circumference as a discriminator of body mass index (overweight, obesity) and waist circumference (moderate risk, high risk) in physically active older women.

\begin{tabular}{llccccc}
\hline & & $\mathrm{n}$ & NC cut-off\& & Sensitivity (\%) & Specificity (\%) & p-value \\
\hline \multirow{2}{*}{ BMI } & Overweight & 96 & $33.07 \mathrm{~cm}$ & 64.2 & 86.2 & $0.0001^{*}$ \\
& Obesity & 103 & $34.05 \mathrm{~cm}$ & 82.4 & 93.1 & $0.0001^{*}$ \\
\multirow{2}{*}{ WC } & Moderate risk & 60 & $32.15 \mathrm{~cm}$ & 82.9 & 56.0 & $0.0014^{*}$ \\
& High risk & 135 & $34.15 \mathrm{~cm}$ & 72.7 & 88.0 & $0.0001^{*}$ \\
\hline
\end{tabular}

NC: neck circumference; BMI: body mass index; WC: waist circumference.

\& Adequate value of NC to discriminate BMI (overweight/obesity) and WC (moderate risk/high risk). * $p<0.01$. 

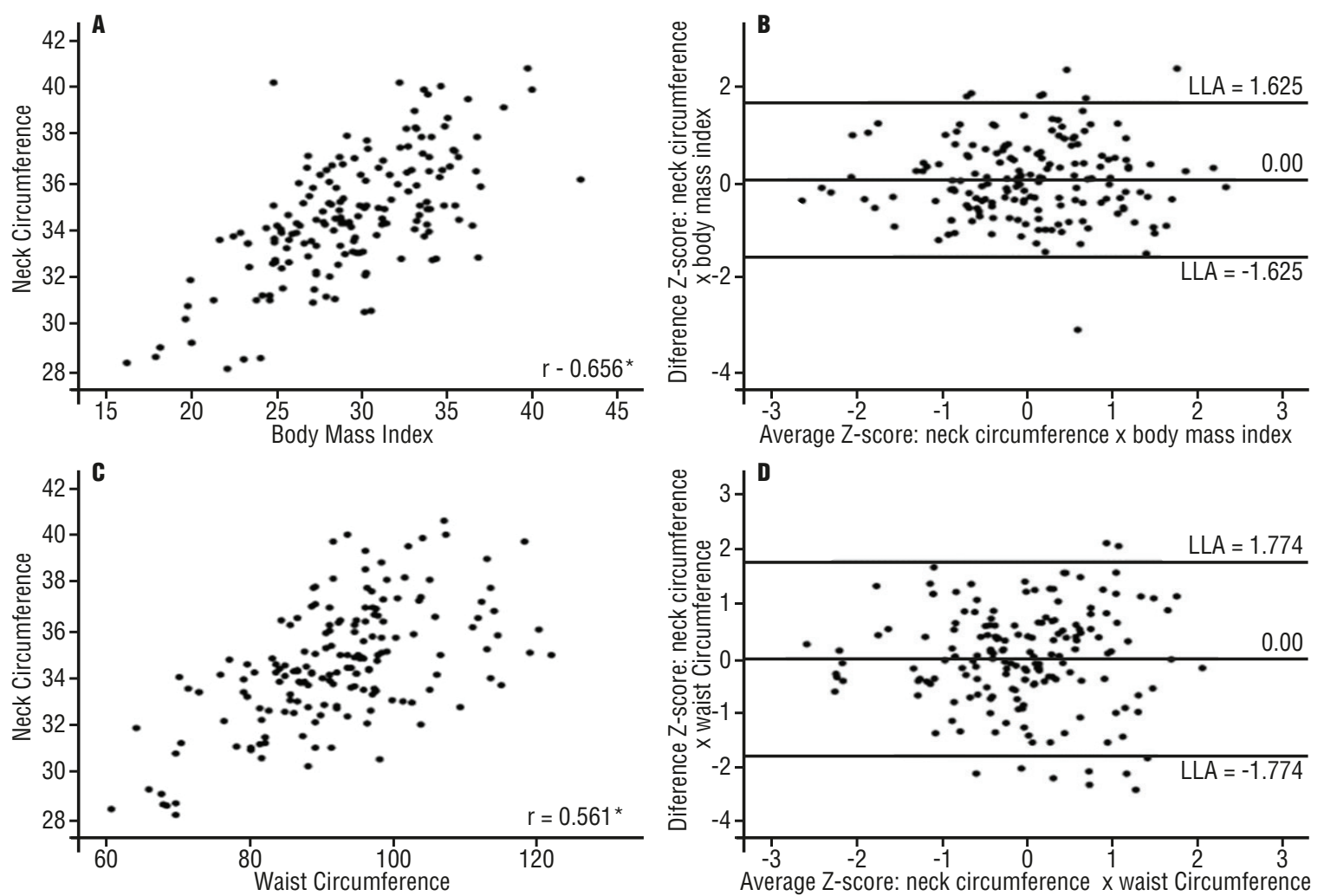

Figure 1. Correlation and agreement between neck circumference and body mass index and between neck circumference and waist circumference $(n=170)$

A and C. Correlation (Spearman/Pearson). B and D. Agreement (Bland-Altman). ULA: upper limit of agreement; LLA: Iower limit of agreement. * Significant correlation by Pearson's test. " Significant correlation by Spearman's test.
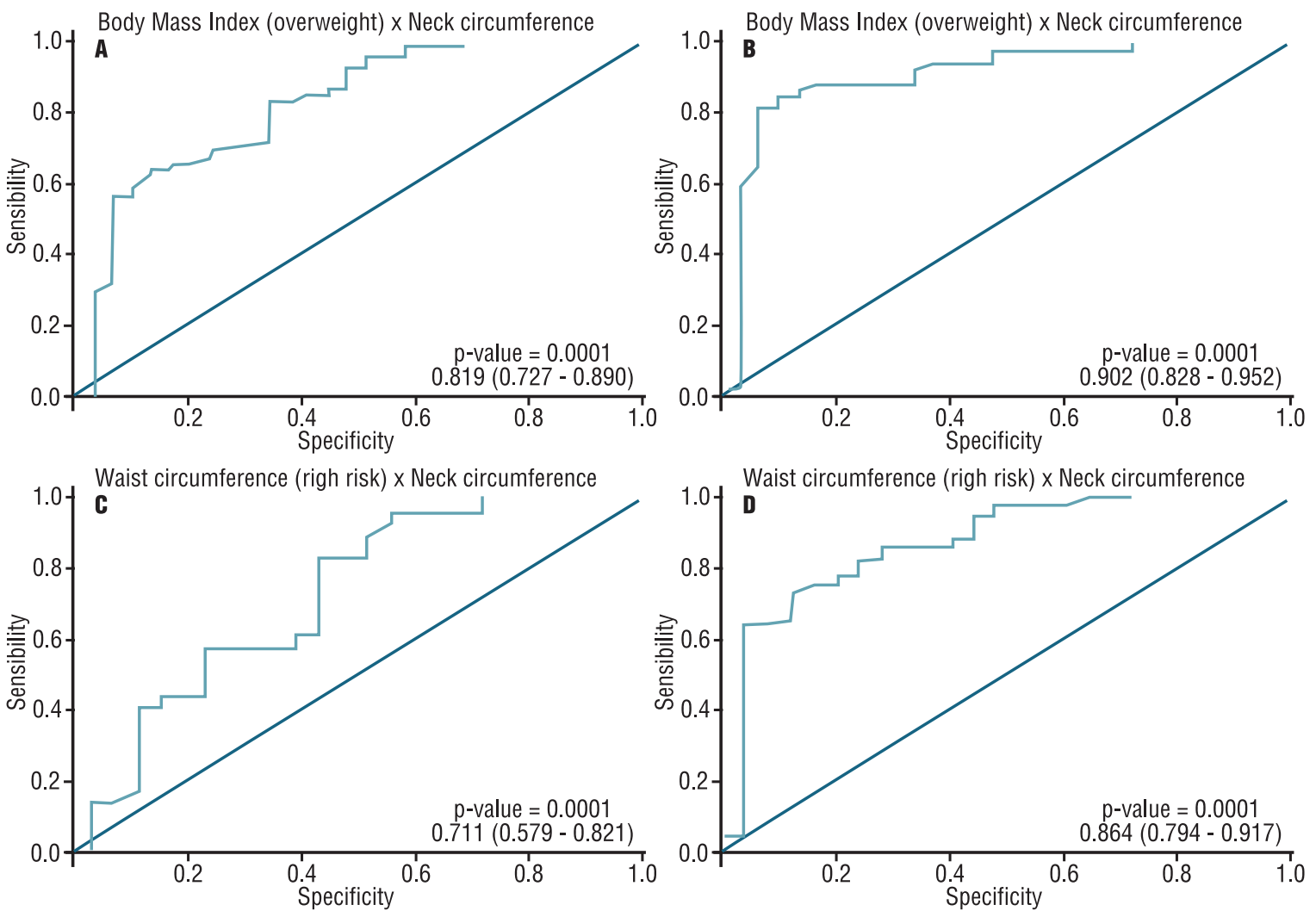

Figure 2. Area under the ROC curve and 95\% confidence interval between neck circumference (NC) and body mass index (BMI; overweight and obesity) and between NC and waist circumference (WC; moderate and high risk) $(n=170)$. 


\section{DISCUSSION}

An important finding of the present study was that $\mathrm{NC}$ was significantly correlated with the anthropometric measurements BMI and WC. In addition, the NC cut-off points to discriminate obesity and a high risk of abnormal body fat distribution showed a sensitivity and specificity higher than $70 \%$, characterizing an adequate capacity to detect body fat distribution in different groups (obese vs non-obese; high risk vs no risk).

High prevalences of overweight and obesity (82.8\%) classified based on BMI and of WC values above the recommended levels (85.2\%) were observed. Similar values for BMI have been reported in a national study conducted in Brazilian capitals ${ }^{24}$ and for WC in a study involving women from the southeastern region of Brazil25.

Although the mechanism underlying the relationship between NC and the occurrence of metabolic problems is not well understood ${ }^{13}$, this measurement has been suggested as an alternative and innovative approach ${ }^{12}$ and is used as a simple, rapid $^{26}$ and reliable method ${ }^{9}$ for the identification of obesity. Joshipura et al. ${ }^{27}$, studying 1,206 older adults aged 40 to 65 years, found a correlation of $\mathrm{NC}$ with $\mathrm{BMI}$ of $\mathrm{r}=0.66$ and with $\mathrm{WC}$ of $\mathrm{r}=0.64$. Yan et al. ${ }^{13}$ reported correlations of $\mathrm{NC}$ with $\mathrm{BMI}$ and $\mathrm{WC}$ of $\mathrm{r}=0.70$ and $\mathrm{r}=0.72$, respectively, in 1,121 Chinese older women. These values are significant and similar to those obtained in this study, demonstrating the relationship between anthropometric methods and highlighting the relevance of this measurement even when used in populations with different characteristics.

This study suggested cut-off points based on the sensitivity and specificity values derived from the ROC curve. Regarding BMI, an $\mathrm{NC} \geq 33.07$ $\mathrm{cm}$ can discriminate overweight and a value $\geq 34.05 \mathrm{~cm}$ can predict obesity. Higher NC cut-off points have been reported by Ben-Noun, Sohar, Laor ${ }^{26}$ who studied 519 middle-aged Israeli women and found values $\geq 34.0$ and $\geq 36.5 \mathrm{~cm}$ to discriminate overweight and obesity, respectively. Yan et al. ${ }^{13}$ also reported higher $\mathrm{NC}$ values in relation to $\mathrm{BMI}$ for 1,121 Chinese older women. In that study, an $\mathrm{NC} \geq 35 \mathrm{~cm}$ discriminated a higher risk of metabolic syndrome and obesity in older women.

With respect to WC, despite the observation of lower sensitivity and specificity compared to the correlation between NC and BMI, a good area under the curve was obtained, with an $\mathrm{NC} \geq 32.15 \mathrm{~cm}$ discriminating a moderate risk and $\geq 34.15$ a high cardiovascular risk. The more accurate predictive capacity of $\mathrm{NC}$ in relation to $\mathrm{BMI}$ compared to WC might be explained by the fact that $\mathrm{BMI}$ is a measure of body proportionality, while $\mathrm{WC}$ is measured at a specific site to verify body fat distribution.

Comparing $\mathrm{NC}$ and WC, a study involving 153 obese women aged 40 to 70 years established a cut-off point of $\mathrm{NC} \geq 35 \mathrm{~cm}$ using binary logistic regres$\operatorname{sion}^{14}$. Moreover, the authors concluded that, in individuals with severe obesity, $\mathrm{NC}$ has a better performance than WC for the evaluation of metabolic health ${ }^{14}$.

As mentioned earlier, the cut-off points of NC differed between studies. This variation might be due to differences in the characteristics of the 
samples such as age group and ethnic background, as well as differences in the measurement techniques of NC. Our study included older women (> 60 years) who performed physical activity. In addition, NC was measured according to the protocol proposed by ISAK, which establishes its measurement immediately above the thyroid cartilage. This technique was chosen because it uses an international protocol that has standardized anthropometric techniques ${ }^{28}$. However, other sites of measurement such as $0.1 \mathrm{~cm}$ below the thyroid cartilage ${ }^{27}$ and at the level of the thyroid cartilage ${ }^{18}$ have been reported.

Finally, although BMI and WC are relatively low-cost and simple methods that require little equipment, $\mathrm{NC}$ can be used as another indicator of obesity both in clinical practice and in epidemiological studies ${ }^{9}$. Neck circumference is a good option when professionals do not have a scale and stadiometer or private room for the measurement of body weight, height and WC where the individual needs to undress. It may also be an alternative in places and on days of low temperatures since the measurement site is easily accessible and normally not impeded by clothing.

Considering the comparison of $\mathrm{NC}$ with $\mathrm{BMI}$ and $\mathrm{WC}$ and the cut-off points established, a value $\geq 34 \mathrm{~cm}$ was found to indicate disturbances and body fat distribution in physically active older women. However, caution is needed when the cut-offs established in this study are used since they were based on doubly indirect measures, BMI and WC. It is important that the population evaluated is similar and that the measurement technique is accurate, taking into consideration inter- and intraobserver technical errors of measurement.

The use of NC combined with BMI, WC and body composition tests is recommended. Further studies are needed that involve larger samples, age stratification, inclusion of men, and validation of this measure using gold standards such as dual-energy x-ray absorptiometry or hydrostatic weighing. In addition, we suggest the establishment of cut-off points of NC to discriminate cardiovascular and metabolic diseases in physically active older women, as well as comparison with the predictive capacity of BMI and WC.

\section{CONCLUSION}

Neck circumference is a good discriminator of overweight, obesity and body fat distribution in physically active older women when compared to BMI and WC. A cut-off point of $34 \mathrm{~cm}$ was established as an indicator of obesity and high risk of abnormal body fat distribution.

\section{REFERENCES}

1. Huxley R, Mendis S, Zheleznyakov E, Reddy S, Chan J. Body mass index, waist circumference and waist:hip ratio as predictors of cardiovascular risk-a review of the literature. Eur J Clin Nutr 2010; 64(1):16-22.

2. World Health Organization. Expert Consultation on Diet, Nutrition and the Prevention of Chronic Diseases. Diet, nutrition and the prevention of chronic diseases: report of a joint World Health Organization/United Nations Food and Agriculture WHO/FAO Expert consultation, Geneva, 2002. 
3. Samper-Ternent R, Al Snih S. Obesity in older adults: epidemiology and implications for disability and disease. Rev Clin Gerontol 2012;22(1):10-34.

4. Nazare JA, Smith J, Borel AL, Aschner P, Barter P, Van Gaal L, et al. Usefulness of measuring both body mass index and waist circumference for the estimation of visceral adiposity and related cardiometabolic risk profile (from the INSPIRE ME IAA study). JAMA Cardiol 2015;115(3):307-15.

5. Jaeschke L, Steinbrecher A, Pischon T. Measurement of waist and hip circumference with a body surface scanner: feasibility, validity, reliability, and correlations with markers of the metabolic syndrome. PloS one 2015;10(3): e0119430.

6. Cervi A, Franceschini SDCC, Priore SE. Análise crítica do uso do índice de massa corporal para idosos. Rev Nutr 2005;18(6):765-75.

7. Menezes TND, Rocha FL, Belém PLDO, Pedraza DF. Obesidade abdominal: revisão crítica das técnicas de aferição e dos pontos de corte de indicadores antropométricos adotados no Brasil. Cien Saude Colet 2014;19(6):1741-54.

8. Almeida RT, Almeida MMG, Araújo TM. Abdominal obesity and cardiovascular risk: performance of anthropometric indexes in women. Arq Bras Cardiol 2009;92(5):345-50.

9. Aswathappa J, Garg S, Kutty K, Shankar V. Neck circumference as an anthropometric measure of obesity in diabetes. N Am J Med Sci 2013;5(1):28-31.

10. Nafiu OO, Zepeda A, Curcio C, Prasad Y. Association of neck circumference and obesity status with elevated blood pressure in children. J Hum Hypertens 2014;28(4):263-8.

11. Silva M, Silva EI, Sant'Ana LFR, Priore SE, Franceschini SCC. Perímetro da cintura, relação cintura/estatura e perímetro do pescoço como parâmetros na avaliação da obesidade central em crianças. Rev Paul Pediatr 2014;32(3):273-81.

12. Stabe C, Vasques ACJ, Lima MMO, Tambascia MA, Pareja JC, Yamanaka A, et al. Neck circumference as a simple tool for identifying the metabolic syndrome and insulin resistance: results from the Brazilian Metabolic Syndrome Study. Clin Endocrinol 2013;78(6):874-81.

13. Yan Q, Sun D, Li X, Zheng Q, Li L, Gu C, Feng B. Neck circumference is a valuable tool for identifying metabolic syndrome and obesity in Chinese elder subjects: a community-based study. Diabetes Metab Res Rev 2014;30(1):69-76.

14. Assyov Y, Gateva A, Tsakova A, Kamenov Z. A comparison of the clinical usefulness of neck circumference and waist circumference in individuals with severe obesity. Endocr Res 2017;42(1):6-14.

15. Preis SR, Pencina MJ, D’Agostino RB, Meigs JB, Vasan RS, Fox CS. Neck circumference and the development of cardiovascular disease risk factors in the Framingham Heart Study. Diabetes Care 2013;36(1):e3-e3.

16. Gonçalves VSS, Faria ER, Franceschini SCC, Priore SE. Neck circumference as predictor of excess body fat and cardiovascular risk factors in adolescents. Rev Nutr 2014;27(2):161-71.

17. Preis SR, Massaro JM, Hoffmann U, D’Agostino RB Sr, Levy D, Robins SJ, et al. Neck circumference as a novel measure of cardiometabolic risk: the Framingham Heart Study. J Clin Endocrinol Metab 2010;95(8):3701-10.

18. Formisano A, Bammann K, Fraterman A, Hadjigeorgiou C, Herrmann D, Iacoviello $\mathrm{L}$, et al. Efficacy of neck circumference to identify metabolic syndrome in 3-10-year-old European children: Results from IDEFICS study. Nutr Metab Cardiovasc Dis 2016;26(6):510-16.

19. Santos D, Contarato AAPF, Kroll C, Bertoli M, Czarnobay SA, Figueirêdo $\mathrm{KBW}$, et al. Neck circumference as complementary measure to identify excess body weight in children aged 13-24 months. Rev Bras Saúde Mater Infant 2015;15(3):301-7.

20. Medeiros PA, Streit IA, Sandreschi PF, Fortunato AR, Mazo GZ. Participação masculina em modalidades de atividades físicas de um Programa para idosos: um estudo longitudinal. Cien Saude Colet 2014;19(8):3479-88. 
21. Stewart A, Marfell-Jones M, Olds T, de Ridder H. International standards for anthropometric assessment. ISAK: Lower Hutt, New Zealand. 2011.

22. World Health Organization. Obesity: preventing and managing the total epidemic. Report of a WHO Consultation Group, Geneva. 1997.

23. Pederson D, Gore C. Error en la medición antropométrica. In: Norton K, Olds T, editors. Antropométrica. Argentina: Biosystem Servicio Educativo. 2000: pp.71-86.

24. Brasil. 2015. Vigitel Brasil 2014: vigilância de fatores de risco e proteção para doenças crônicas por inquérito telefônico / Ministério da Saúde, Secretaria de Vigilância em Saúde, Departamento de Vigilância de Doenças e Agravos não Transmissíveis e Promoção da Saúde. - Brasília: Ministério da Saúde, 2015.

25. Orsatti FL, Nahás EAP, Nahas-Neto J, Maestá N, Padoani NP, Orsatti CL. Indicadores antropométricos e as doenças crônicas não transmissíveis em mulheres na pós-menopausa da região Sudeste do Brasil. Rev Bras Ginecol Obstet 2008;30(4):182-9.

26. Ben-Noun LL, Sohar E, Laor A. Neck circumference as a simple screening measure for identifying overweight and obese patients. Obes Res 2001;9(8):470-477.

27. Joshipura K, Muñoz-Torres F, Vergara J, Palacios C, Pérez CM. Neck circumference may be a better alternative to standard anthropometric measures. J Diabetes Res 2016;2016:1-8.

28. Kerr DA, Hume P. ISAK history and importance. Australia. 2015; Available from: <https://www.researchgate.net/publication/283517207_ISAK_history_ and_importance $>$ [2016 sept].

\section{CORRESPONDING AUTHOR}

Corresponding Author Daniel Rogério Petreça 1071, Presidente Nereu Ramos Avenue.

ZIP CODE 89300-000

Mafra, SC - Brazil

Email: profdaniel@unc.br 